\title{
Wound and Conjunctival Myiasis Caused by Lucilia sericata:A Case Report
}

\author{
Soheila Nasiri ${ }^{1}$; Sarah Ershadi ${ }^{1}$; Fahimeh Abdollahimajd ${ }^{1, *}$; Elmira Asadi $^{1}$ \\ ${ }^{1}$ Skin Research Center, Shahid Beheshti University of Medical Sciences, Tehran, IR Iran \\ ${ }^{*}$ Corresponding author: Fahimeh Abdollahimajd, Skin Research Center, Shahid Beheshti University of Medical Sciences, Tehran, IR Iran. Tel: +98-2122741509, Fax: +98-2122744393, \\ E-mail: fabdollahimajd@yahoo.com; fabdollahimajd@sbmu.ac.ir
}

Received: January 16, 2015; Revised: May 11, 2015; Accepted: May 19, 2015

\begin{abstract}
Introduction: Wound myiasis is the infestation of human wounds by dipterous larvae due to Calliphora, Cochliomyia, Phormia and Lucilia species. Ophthalmomyiasis is rare and is classified into external, internal, or orbital categories. External ophthalmomyiasis (the most common type) refers to an infestation of the conjunctiva and palpebra, mainly caused by the sheep bot fly(Oestrus ovis).

Case Presentation: We describe a young male with wound and ocular myiasis due to Lucilia sericata, who had a history of trauma to his scalp following a car accident during the previous few days and was left about three days in an inaccessible area. He complained of painful parietal ulcer and sudden onset of left eye redness with pain. Physical examination revealed wound and conjunctival myiasis. The larvae were manually extracted by forceps and seven days later, the lesions showed improvement.

Conclusions:Earlydiagnosisisrequired for themanagementof human myiasis.If we don't properlyrecognizeand treatophthalmomyiasis, it can progress rapidly and can result in destruction of orbital tissues. The main treatment modality includes removal of the larvae and if necessary, surgical debridement.
\end{abstract}

Keywords: Wounds and Injuries; Myiasis; Conjunctiva; Ectoparasitic Infestations; Lucifensin

\section{Introduction}

Myiasis is an infestation of vertebrate animals and live humans with dipterous larvae, which feed on the host's tissues (dead or living) or liquid substances (1). The larvae require warm temperature to incubate; thus most infestations are found during summer and in tropical countries (2). Cutaneous myiasis occurs when flies oviposit in wounds or on the skin, followed by invasion of the larvae into the subdermis (3). Also they may enter an orifice of the host with no tissue invasion. This has been defined as pseudomyiasis (3). Myiasis has been classified based on the involved site of the body. The most frequent type is cutaneous myiasis that manifests as wound, migratory or furuncular forms (1). Also other sites of infestation have been reported, such as nasopharyngeal, ophthalmic, urogenital and intestinal (3). The aim of this report was to discuss a clinical case of cutaneous and ocular myiasis caused by Lucilia sericata in a young male patient.

\section{Case Presentation}

A 22-year-old man was seen in a dermatology clinic (Loghman-e Hakim hospital, Shahid Beheshti University of Medical Sciences, Tehran, Iran), during August 2013 because of a recent singular and painful parietal ulcer and sudden onset of left eye redness with pain. He had a history of trauma to his scalp following a car accident a few days before. He said that he had attempted driving on a low traffic road after ingestion of 20 tramadol tablets for suicidal ideas. He lost the balance of the car and the car was diverted. He was left for about three days in an inaccessible area and brought to the hospital by a passenger. He noticed the presence of numerous small worm-like structures over his ulcer, complained about a movement and itching sensation within the ulcer.

Physical examination revealed a $2 \times 3 \mathrm{~cm}$ mass of numerous mobile larvae on the left parietal scalp (Figure 1). There was no evidence of surrounding cellulitis or induration. Forty-three larvae were manually extracted by forceps. Our patient received diphtheria and tetanus toxoids (DT) vaccine ( $0.5 \mathrm{mg} /$ intramuscularly) and also tetabulin immunoglobulin (500 mg/intramuscularly). Ophthalmic inspection revealed left-sided conjunctival hyperemia and mild chemosis with obvious discomfort. The patient was referred to an ophthalmologist. Slit lamp examination revealed tiny larvae (Figure 2). After local anesthesia, the external parasites were immediately removed under slit lamp examination without bleeding. No parasites had penetrated the sclera or into the orbit and also the anterior chamber; the vitreous cavity and fundus were normal. One larva was sent to the microbiology department and was identified as that of the green bottle fly Lucilia sericata. Laboratory tests were within normal ranges (fasting blood glucose, complete blood count, and erythrocyte sedimentation rate). Cranial computed tomographic scan was normal. Seven days later,

Copyright (C) 2015, Infectious Diseases and Tropical Medicine Research Center. This is an open-access article distributed under the terms of the Creative Commons Attribution-NonCommercial 4.0 International License (http://creativecommons.org/licenses/by-nc/4.0/) which permits copy and redistribute the material just in noncommercial usages, provided the original work is properly cited. 
Figure 1. Photograph of Wound Myiasis (by Lucilia sericata) on the Left Parietal Scalp

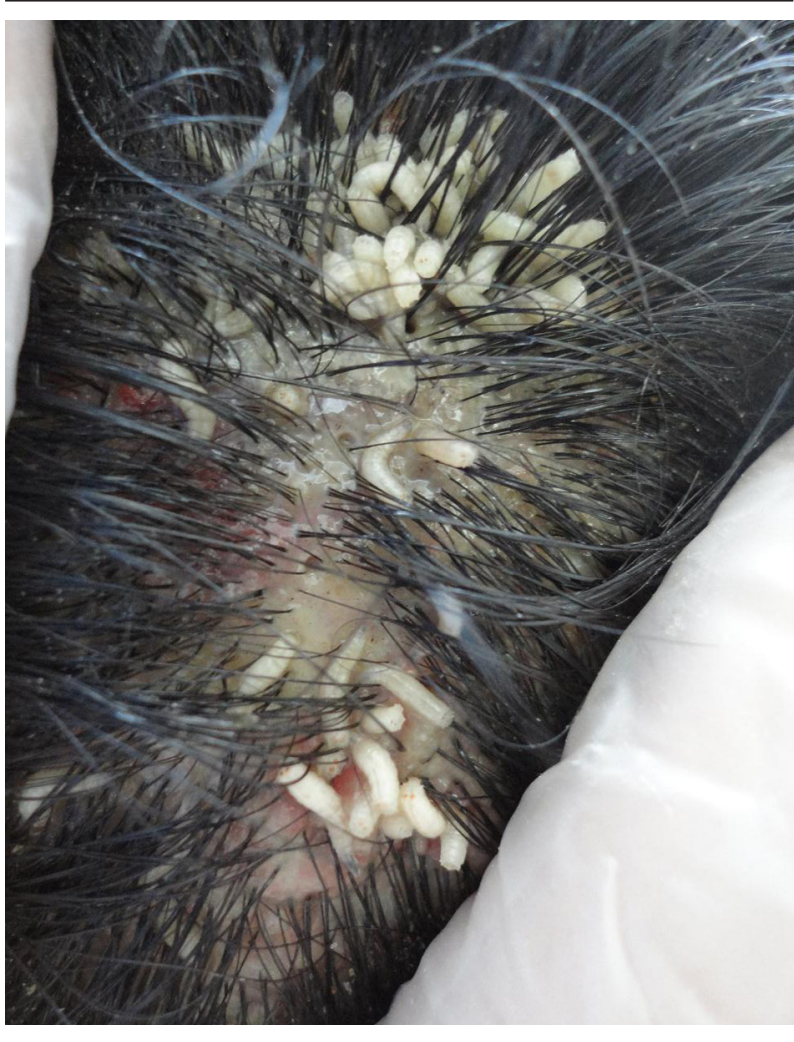

Numerous yellow larvae are present in the wound.

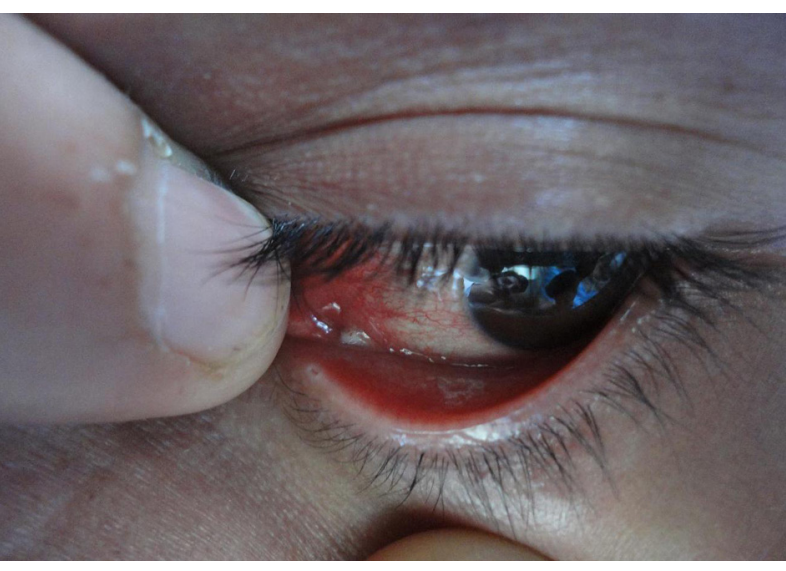

Figure 2. Pre-Treatment Picture Showing Conjunctival Redness and Also a Larva (Lucilia sericata)

the patient was re-examined. Re-examination of the skin and eye revealed no larvae and the lesions had shown improvement.

\section{Discussion}

Human myiasis has been classified both based on the affected site and the oviposition habits of the flies. Obli- gate parasites need live tissue for growth. Opportunistic flies prefer nonliving organic substances such as vegetables, and incidentally open wounds (1). Classification of myiasis based on the involved site of the body is more practical. The most frequent type is cutaneous myiasis that manifests as wound or traumatic, migratory and furuncular forms (1). Also, nasopharynx, urogenital, intestine and orbit are less commonly involved (3). Wound myiasis occurs when larvae penetrate open wounds (1). Common species in wound myiasis are Calliphora, Cochliomyia, Phormia and Lucilia $(1,4)$. Yasin et al. (5) reported on a 62-year-old homeless male from Iran with a wound myiasis caused by the larva of Lucilia sericata in his previously punctured neck. In our case, wound myiasis was due to Lucilia sericata.

In addition to open wound, subsequent predisposing factors have been recognized for infestation:

- Debilitated patients (mental or physical dependency), poor hygiene, diabetes, immune suppression;

- Bleeding or presence of necrotic tissue;

- Summer season;

- Physical inability to prevent flies from oviposition (2-4) such as our patient in this case report.

Ophthalmomyiasis refers to ocular and orbital involvement that is rare and is found in every part of the world $(6,7)$. It is classified into external, internal, or orbital, based on the affected site. External ophthalmomyiasis (the most common type) refers to an infestation of the conjunctiva and palpebra by the larvae from the order Diptera. The manifestation of external ophthalmomyiasis is similar to conjunctivitis, including redness, itching, chemosis and foreign body sensation. If the Larvae penetrate the sclera and move into the subretinal space, internal ophthalmomyiasis appears (6, $7)$. Orbital myiasis refers to the destruction of orbital content (7). Ophthalmomyiasis is mainly caused by the sheep botfly (Oestrus ovis), while another common species is cattle botfly (Hypoderma bovis) (8), and it is very rarely caused by Lucilia sericata (9). Kersten et al. (10) presented the first case of orbital myiasis with invasion of the orbital apex caused by larvae of Chrysomya bezziana Villeneuve. The patient underwent exenteration for prevention of intracranial invasion. Khataminia et al. (6) reported a case of massive orbital myiasis caused by Chrysomya or old world screw-worm fly. Cameron et al. (11) reported on three patients with external ophthalmomyiasis caused by Oestrus ovis, for whom the symptoms and signs improved after removal of the larvae. There are rare reports about ophthalmomyiasis externa caused by Lucilia sericata, a green bottle fly. Kalezic et al. (8) presented the first case report of external ophthalmomyiasis in an old female from Belgrade caused by Lucilia sericata. Yasin et al. (9) reported on an 80-yearold woman with ophthalmomyiasis from Iran caused by Lucilia sericata larva in her nucleated eye because of invasive basal cell carcinoma. Although in principal, $\mathrm{Lu}$ - 
cilia sericata larvae infest carrion breeders, yet they can develop on different types of waste materials including meat scraps. Also, human infestation may occur. They have strong attraction to non-healing and malodorous wounds and necrotic areas (8). Ophthalmomyiasis may lead to blindness, disfigurement, rarely intracranial involvement and unexpected death (7).

One treatment modality is the removal of the larvae from the infected areas. One approach for larval removal is occlusion-suffocation in which petroleum, liquid paraffin, or heavy oil are placed over the affected site, then the aerobic larva comes to the surface for air; at this point, they are gently caught by forceps. If parts of the body of larvae remain, a foreign body reaction can be found; thus one should be cautious when removing the larvae. Another method is the use of insecticides. Exenteration is used for treatment of cases with severe ophthalmomyiasis. Wound management is also very important in treatment; antiseptic dressings and antibiotics are often used and tetanus vaccination is recommended. One adjunctive therapy for some specific cases of ophthalmomyiasis is ivermectin (6).

Although there is no absolute method for protection against myiasis, yet good personal hygiene, wounds and necrotic tissue protection against flies, treatment of debilitating conditions, and also management of food residues and waste material containers are the best preventive modalities $(6,12)$.

\section{Acknowledgements}

We sincerely thank Dr. Karami for managing this patient and providing technical help, yet he didn't have the criteria of authorships.

\section{Authors' Contributions}

Data gathering and drafting of the manuscript were performed by Fahimeh Abdollahimajd, Sarah Ershadi and Elmira Asadi. Critical revision of the manuscript was made by Soheila Nasiri and Fahimeh Abdollahimajd.

\section{References}

1. Safdar N, Young DK, Andes D. Autochthonous furuncular myiasis in the United States: case report and literature review. Clin Infect Dis. 2003;36(7):e73-80.

2. Soleimani-Ahmadi M, Vatandoost H, Hanafi-Bojd AA, Poorahmad-Garbandi F, Zare M, Hosseini SM. First Report of Pharyngostomy Wound Myiasis Caused by Chrysomya bezziana (Diptera: Calliphoridae) in Iran. J Arthropod Borne Dis. 2013;7(2):194-8.

3. Predy G, Angus M, Honish L, E. Burnett C, Stagg A. Myiasis in an urban setting: A case report. Can J Infect Dis. 2004;15(1):51-2.

4. Terterov S, Taghva A, MacDougall M, Giannotta S. Posttraumatic human cerebral myiasis. World Neurosurg. 2010;73(5):557-9.

5. Yasin M, Gozali Asl N, Moghhtader Mojdehi A, Mardani M, Akbarzadeh K. Wound Myiasis in a Sixty-Two-Year-Old Man. Archives of Clinical Infectious Diseases. 2014;9(2):e19659.

6. Khataminia G, Aghajanzadeh R, Vazirianzadeh B, Rahdar M. Orbital myiasis. J Ophthalmic Vis Res. 2011;6(3):199-203.

7. Yeung JC, Chung CF, Lai JS. Orbital myiasis complicating squamous cell carcinoma of eyelid. Hong Kong Med J. 2010;16(1):63-5.

8. Kalezic T, Stojkovic M, Vukovic I, Spasic R, Andjelkovic M, Stanojlovic S, et al. Human external ophthalmomyiasis caused by Lucilia sericata Meigen (Diptera: Calliphoridae)-a green bottle fly. $J$ Infect Dev Ctries. 2014;8(7):925-8.

9. Yasin M, Moghhtader Mojhdehi A, Haghighi M, Akbarzadeh K. Ophthalmomyiasis and Basal Cell Carcinoma: a Case Report. Archives of Clinical Infectious Diseases. 2013;8(3):e15336.

10. Kersten RC, Shoukrey NM, Tabbara KF. Orbital myiasis. Ophthalmology. 1986;93(9):1228-32.

11. Cameron JA, Shoukrey NM, al-Garni AA. Conjunctival ophthalmomyiasis caused by the sheep nasal botfly (Oestrus ovis). Am J Ophthalmol.1991;112(3):331-4.

12. Caissie R, Beaulieu F, Giroux M, Berthod F, Landry PE. Cutaneous myiasis: diagnosis, treatment, and prevention. J Oral Maxillofac Surg. 2008;66(3):560-8. 